\title{
An Evaluation of the Family Informal Caregiver Stroke Self-Management Program
}

\author{
Gail Mores, Rhonda McNicoll Whiteman, Jenny Ploeg, Patricia Knobl, \\ Miriam Cahn, Laura Klaponski, Ann Lindley, Kathy Fisher
}

\begin{abstract}
Background: Caregivers are often unprepared and overwhelmed with the responsibilities of providing care to stroke survivors, which can lead to negative physical and psychological effects. Purpose: To evaluate the impact of the Family Informal Caregiver Stroke SelfManagement (FICSS) program on burden and life changes resulting from providing care among family caregivers of stroke survivors. Methods: A prospective pre-test and post-test design using quantitative and qualitative data was used to evaluate the program with a convenience sample of 42 caregivers. The four-module facilitated program consisted of small group-guided discussion. Quantitative evaluations were completed at baseline, 2 weeks and 6 months (post-intervention), and qualitative data were collected at 2 weeks and 6 months. Life changes and burden were measured using the Bakas Caregiving Outcome Scale (BCOS) and the Oberst Caregiving Burden Scale (OCBS), respectively. Results: The BCOS scores increased consistently over time, showing significant differences at 6 months compared with 2 weeks (mean difference: $5.29,95 \%$ confidence interval $[\mathrm{CI}]: 0.30-10.28, p=0.04$ ) and baseline (mean difference: $7.58,95 \% \mathrm{CI}: 2.92-12.23$, $p=0.001$ ). The OCBS time scores decreased consistently over time, showing a significant difference at 6 months compared with baseline (mean difference: $-5.20,95 \%$ CI: -0.96 to $-9.44, p=0.02$ ). The OCBS difficulty scores fluctuated over time, resulting in no overall difference from baseline to 6 months. Qualitative themes were consistent with the positive quantitative findings. Conclusion: Study results suggest that the FICSS program may result in reduced caregiver burden and improved life changes resulting from providing care.
\end{abstract}

RÉSUMÉ: Évaluation du programme Family Informal Caregiver Stroke Self-Management. Contexte: Les aidants naturels sont souvent mal préparés et dépassés par les responsabilités liées au fait de prendre soin d'une personne ayant survécu à un AVC, ce qui peut entrainer chez eux des effets négatifs tant sur le plan physique que sur le plan psychologique. Objectif: En tenant compte des changements à leur mode de vie et du fardeau qui est le leur, évaluer l'impact du programme Family Informal Caregiver Stroke Self-Management (FICSS) sur les aidants naturels prenant soin de personnes ayant survécu à un AVC. Méthodes: Un modèle prospectif pré-test et post-test faisant appel à des données qualitatives et quantitatives a été utilisé afin d'évaluer ce programme. Pour ce faire, nous nous sommes limités à un échantillon de commodité formé de 42 aidants naturels. Divisé en quatre modules, le FICSS consiste en une série de discussions menées en petits groupes. Des évaluations quantitatives ont été complétées au départ de cette étude ainsi que deux semaines et six mois plus tard (post-intervention); des données qualitatives ont également été collectées deux semaines et six mois après le début de l'étude. Le fardeau reposant sur les aidants naturels de même que les changements à leur mode de vie ont été mesurés respectivement au moyen de la Bakas Caregiving Outcomes Scale (BCOS) et de l'Oberst Caregiving Burden Scale (OCBS). Résultats: Les scores à la BCOS ont augmenté de façon constante au fil du temps, un écart important étant noté entre les scores obtenus après six mois par rapport à ceux obtenus après deux semaines (différence moyenne: 5,29, IC 95 \%: 0,30 à 10,28, $p=0,04$ ) et au départ (différence moyenne: 7,58, IC 95 \%: 2,92 à 12,23,p=0,001). Les scores obtenus à l'OCBS ont par ailleurs diminué de façon constante au fil du temps, un écart notable étant noté entre les scores obtenus après six mois par rapport à ceux obtenus au départ de l'étude (différence moyenne: $-5,20$, IC $95 \%$ : $-0,96$ à $-9,44, p=0,02$ ). Si les scores de l'OCBS indiquant des difficultés dans la prise en charge ont aussi fluctué avec le temps, nous n'avons pas noté de différence générale entre les débuts de l'étude et la période subséquente de six mois. Enfin, les aspects abordés sur le plan qualitatif se sont avérés conformes à nos observations positives sur le plan quantitatif. Conclusions: Les résultats de notre étude suggèrent donc que le programme FICSS pourrait entraîner une réduction du fardeau imposé aux aidants naturels et une amélioration de leur mode de vie en dépit de l'impact que représente le fait de prodiguer des soins.

Keywords: Family caregivers, Stroke, Self-management

doi:10.1017/cjn.2018.335

Can J Neurol Sci. 2018; 45: 660-668

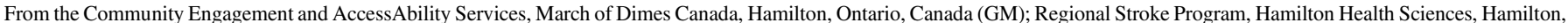

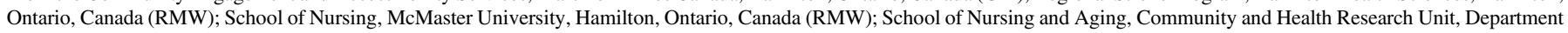

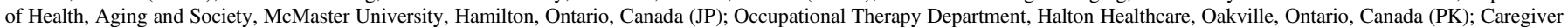

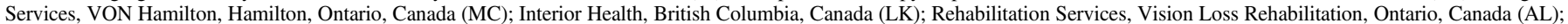
School of Nursing and Aging, Community and Health Research Unit, McMaster University, Hamilton, Ontario, Canada (KF).

Received May 17, 2018. Final Revisions Submitted July 17, 2018. Date of Acceptance August 15, 2018.

Correspondence to: G. Mores, 1550 Upper James, Suite 302, Hamilton, Ontario, Canada L9B 2L6. Email: gmores@marchofdimes.ca 


\section{INTRODUCTION}

Each year approximately 62,000 Canadians experience a stroke. ${ }^{1}$ Although the majority of individuals who experience a stroke are discharged home, many are left with ongoing impairments, such as hemiparesis, cognitive deficits, aphasia, visual impairments and difficulties with activities of daily living. ${ }^{2}$ As a result of this ongoing functional disability, many stroke survivors depend on the assistance of a family caregiver to help them meet their needs.

Owing to the sudden onset of stroke, the role of caregiver comes unexpectedly and without adequate time to prepare for the role. ${ }^{3}$ Caregivers must suddenly assist with the stroke survivor's day-to-day activities, such as bathing, toileting, mobilization, meal preparation, transportation and navigating the health care system. ${ }^{4}$ They often have difficulty coping with the sudden changes in their roles, the unpredictable nature of stroke recovery and the variety of impairments experienced post stroke. ${ }^{5,6}$ Caregivers experience increased physical and psychological demands and consequently have less time to allocate to their own health needs. The new and unbalanced responsibilities and the lack of preparation for the role may therefore have negative implications for the caregiver. ${ }^{7,8}$ Although education and support programs may help caregivers cope with the changes in their role, we know little about the impact of such programs on caregiver outcomes. The purpose of this paper is to describe the impact of the Family Informal Caregiver Stroke Self-Management (FICSS) program on burden and life changes resulting from providing care among family caregivers of stroke survivors.

\section{LITERATURE REVIEW}

The high demands and duration of care required for stroke survivors can physically and psychologically drain caregivers, placing them at risk of negative outcomes, such as depressive symptoms, psychosocial impairment, a decline in physical health and, more importantly, a decrease in their quality of life. ${ }^{6,9-13}$ The Canadian Stroke Best Practice Recommendations ${ }^{14}$ contain recommendations regarding the education and support of family caregivers. The recommendations focus on: (a) assessing and preparing family and caregivers for transitions between stages of care and care settings through information sharing, provision of education, skills training, psychosocial support and awareness of community services; (b) completing a comprehensive assessment of family and caregivers regarding their current health status, employment and social responsibilities and how these will be managed in providing stroke care, caregivers capabilities and experience in providing care to the person affected by stroke, resource issues and support from other family members, relatives and social networks; (c) ensuring appropriate referrals to appropriate care professionals to address issues identified; (d) providing support to families and caregivers in hospital and after discharge to the next stage or setting of care using a variety of modalities including telemedicine technology; (e) educating families and caregivers across the continuum of stroke care and (f) providing families with information regarding peer support groups in the community and facilitating these connections.

Stroke survivors and their caregivers receive support and education while in the hospital. However, once the stroke survivor returns home, caregivers often report not receiving enough training for their new responsibilities. ${ }^{15}$ During this transition, caregivers may experience difficulty coping and accessing community services and may lose social support. Therefore, caregivers require programs that provide additional training to manage their new roles and the stress associated with those roles, as well as resources to increase emotional and community support. Recent literature supports the need for programs to address caregiver burden and psychological distress of caregivers. ${ }^{13,15-17}$ Interventions targeting caregivers have demonstrated improved caregiver knowledge, problem-solving, confidence and selfefficacy and decreased caregiver stress, strain and burden. ${ }^{18} \mathrm{~A}$ systematic review to determine the most effective psychosocial intervention for family caregivers of stroke survivors compared a variety of interventions, including individual and group psychotherapy, face-to-face and telephone programs. ${ }^{16}$ Owing to the small number of programs in this area, the authors were unable to determine the most effective intervention. However, they recommend including core skills of problem-solving, coping with stress, stroke-related education and caregiving skills training programs to equip family caregivers to face the challenges of caregiving. Similarly, the Heart and Stroke Foundation of Canada ${ }^{19}$ emphasizes the need for programs that include education for patients and families related to stroke, including understanding the nature and causes of stroke, and the promotion of self-management. Although the needs of family caregivers of stroke survivors are well recognized, they are not well addressed with existing services.

The FICSS was developed to address the unmet needs of family caregivers of stroke survivors. The pilot program comprised four modules including: (a) balancing changing roles and responsibilities; (b) managing cognitive, perceptual and mood changes of the stroke survivor; (c) dealing with sexuality and intimacy and (d) accessing community resources and linkage with allied health professionals in the community. The program provided opportunities for caregivers to share their stories and learn from each other in addition to developing new strategies and coping mechanisms. The results from a very small pilot evaluation $^{20}$ supported the need for an education and support program for this population and indicated a number of recommendations to improve the FICSS program, which were integrated into the design of the current intervention.

\section{MeTHODS}

\section{Study Purpose}

The purposes of this study were to (a) evaluate the impact of the FICSS program on burden and life changes resulting from providing care among family caregivers of stroke survivors and (b) describe the perceptions of caregivers related to perceived impact of the FICSS program and recommendations for program change.

\section{Study Design}

A prospective pre-test and post-test study design incorporating quantitative and qualitative data was used. Quantitative data were used to assess effectiveness of the program on caregiver outcomes (a deductive approach), whereas qualitative data were used to assess the perspectives of participants (an inductive approach) related to their experiences with the program, perceived impact and recommendations for change. For the qualitative component, Sandelowski's qualitative description approach was used. ${ }^{21,22}$ 


\section{Participants and Setting}

A convenience sample of 42 informal family caregivers who were 18 years or older, spoke English and had been caring for stroke survivors at home participated in the study. The study took place within the central south Ontario stroke region, which encompasses the Hamilton, Niagara, Haldimand, Brant, Waterloo and Wellington Counties of Ontario, Canada. Recruitment was undertaken by providing education about the project, email communication and distribution of flyers to stroke recovery groups and associations, community support agencies, hospital outpatient rehabilitation projects, and regional and district stroke centers. Information about the study was also provided in the local media, local websites and newsletters of March of Dimes Canada/ Stroke Recovery Canada and $\mathrm{VON}^{\circledR}$ Hamilton.

\section{Intervention}

The FICSS program consisted of a four-module series consisting of 2 hours weekly small group-guided discussion and problem-solving sessions. The program was facilitated by a social worker who provides similar programs for caregivers of people with dementia and a health promoter specializing in supporting stroke survivors and their caregivers. The first two modules focused on: (a) sharing your story and (b) community connections. Modules 3 and 4 were chosen by participants from the following options: (a) Communication: key for caregivers; (b) Behavior changes: mood, thought and perception; (c) Stress management: managing the rollercoaster; (d) Changing roles in your relationship; (e) Dealing with emotions: anger, grief and loss and (f) How to be caregiver-smart.

Program objectives were to improve caregiver self-management skills and ability to cope. The program was developed based on a literature review, a series of focus groups with family caregivers of stroke survivors and a review of existing programs. The modules include the principles of self-management based on the Southwest Stroke Region self-management toolkit. ${ }^{23,24}$ Eight groups were offered at various geographic locations across the region and were composed of 4-7 caregivers (mean $=5$ ). Of the 42 participants who attended the program, $29(69 \%)$ attended all four sessions, four $(9.5 \%)$ attended three sessions and nine $(21 \%)$ attended two sessions.

\section{Data Collection}

Data collection occurred from April 2011 to January 2013. Baseline demographic and health information related to the caregiver and stroke survivor were collected using the 24-item Caregiver Baseline/Stroke Survivor Baseline Questionnaire. ${ }^{15}$ The Bakas Caregiving Outcome Scale ${ }^{25}$ (BCOS) and the Oberst Caregiving Burden Scale ${ }^{26}$ (OCBS) were completed by participants at baseline (T1), 2 weeks (T2) and 6 months (T3) post-intervention.

The BCOS is a 15-item self-report instrument using a sevenpoint Likert scale designed to measure both positive and negative changes in post-stroke caregiver family life in the areas of social functioning, subjective well-being and physical health. ${ }^{25}$ The original scale was revised to add five additional items addressing financial well-being, physical functioning, general health, roles in life and level of energy. The revised scale has demonstrated internal consistency reliability of 0.90 and a construct validity of $0.66 .^{25}$ A total scale score ranging from 15 to 105 is created by summing the responses for the 15 items, with a higher score representing a more positive outlook.

The OCBS is a 15-item self-report instrument using a five-point Likert scale to evaluate caregiver perceptions of the time and difficulty associated with 15 tasks performed in caring for recovering family members. ${ }^{26}$ It has been validated in cancer and stroke caregiver populations. ${ }^{26,27}$ It demonstrated internal consistency reliability of $0.90-0.94$ and validity of between 0.61 and 0.82 in stroke caregivers. ${ }^{9}$ Total scores are created for the time and difficulty subscales by summing across the responses to the 15 items. The subscale scores range from 15 to 75 , with higher scores representing more time or more difficulty completing caregiving tasks.

Qualitative data related to caregivers' perceptions of the impact of the program and evaluation of the program were also collected. Face-to-face focus groups were conducted at 2 weeks (T2) and individual telephone interviews were conducted at 6 months (T3) post-intervention. Focus groups and telephone interviews were audio-recorded and transcribed.

\section{Data Analysis}

Quantitative analyses were conducted using SAS version 9.3. Descriptive statistics were calculated for each scale and subscale at three times $(\mathrm{T}): \mathrm{T} 1=$ baseline; $\mathrm{T} 2=2$ weeks and $\mathrm{T} 3=6$ months. Tests were conducted to confirm normality in the outcome distributions before the use of repeated measures analysis of variance (ANOVA) to analyze differences over time in the BCOS and OCBS time and difficulty scores. The significance level was set at $p=0.05$. Of the participants, 40 completed the T2 quantitative instruments and 38 completed the T3 quantitative instruments. Of the 42 included participants, 10 had missing items on the BCOS scale and 13 had missing items on the OCBS scale, and the pattern of missing data appeared to be random (arbitrary). Multiple imputation appropriate for this missing pattern and the distributional properties of the outcomes were used to create five imputed datasets. ${ }^{28}$ Repeated measures ANOVA was performed on each imputed dataset, and the results pooled to determine an estimate of overall effect and significance across the five imputations. A complete case analysis (using only participants with a complete dataset for all outcomes and time points) was performed as a sensitivity analysis.

Qualitative data were analyzed using Braun and Clarke's thematic analysis approach. ${ }^{29}$ Inductive thematic analysis is a method of identifying, analyzing and reporting patterns or themes in the data such that the themes are strongly linked to the data themselves. We used the six phases of thematic analysis: (a) familiarizing ourselves with the data through repeated reading of the transcripts; (b) generating initial codes or ideas about the data; (c) searching for themes by sorting through the coded data; (d) reviewing and refining themes; (e) defining and naming themes and (f) producing the report. Three authors and a student completed the first five phases, and all authors met to review the themes and reached agreement on the themes through discussion.

To ensure trustworthiness of the qualitative results, the study was guided by the accepted principles of credibility, transferability, dependability and confirmability. ${ }^{30}$ The analysis team met frequently to discuss the transcripts, codes and themes and to validate and reach agreement on the final themes. An audit trail was maintained, including analytical decisions to ensure confirmability of results. Rich study information and quotations were 
provided to facilitate credibility of results and transferability to similar contexts and populations.

\section{Ethics}

Ethics approval was obtained from the Hamilton Integrated Research Ethics Board (Approval 16-668) and all participants provided written informed consent.

\section{RESULTS}

\section{Description of Participants}

The mean age of participants was 61.7 years with a range of 38-84 years (see Table 1). Most caregivers were female (71\%), married $(86 \%)$ and had completed some college or university

Table 1: Demographic description of caregivers $(n=42)$

\begin{tabular}{|c|c|}
\hline Variable & Number $(\%)$ \\
\hline \multicolumn{2}{|l|}{ Gender } \\
\hline Female & $30(71.4)$ \\
\hline Male & $12(28.6)$ \\
\hline Age: mean years & 61.7 (range 38-84) \\
\hline \multicolumn{2}{|l|}{ Marital status } \\
\hline Married/common law & $36(85.7)$ \\
\hline Single/separated/divorced & $6(14.3)$ \\
\hline \multicolumn{2}{|l|}{ Highest level of education } \\
\hline Less than secondary school & $3(7.1)$ \\
\hline Completed secondary school & $7(16.7)$ \\
\hline Completed some college & $6(14.3)$ \\
\hline Completed college & $10(23.8)$ \\
\hline Completed some university & $5(11.9)$ \\
\hline Competed university & $9(21.4)$ \\
\hline Missing & $2(4.8)$ \\
\hline \multicolumn{2}{|l|}{ Income } \\
\hline$<\$ 29,999$ & $4(9.5)$ \\
\hline$\$ 30,000-\$ 39,999$ & $4(9.5)$ \\
\hline$\$ 40,000-\$ 49,999$ & $5(11.9)$ \\
\hline$\$ 50,000-\$ 69,999$ & $7(16.7)$ \\
\hline$>\$ 70,000$ & $12(28.6)$ \\
\hline Missing & $10(23.8)$ \\
\hline \multicolumn{2}{|l|}{ Birth place } \\
\hline Canada & $33(78.6)$ \\
\hline Other & $9(21.4)$ \\
\hline \multicolumn{2}{|l|}{ Relationship with stroke survivor } \\
\hline Spouse & $31(73.8)$ \\
\hline Daughter/son & $6(14.3)$ \\
\hline Mother/father & $3(7.1)$ \\
\hline Other & $2(4.8)$ \\
\hline Living with stroke survivor: yes & $39(92.9)$ \\
\hline Length of time as caregiver: mean number of years & 4.6 (range $0.3-22.2$ ) \\
\hline Receiving community support: yes & $19(45.2)$ \\
\hline
\end{tabular}

education. Most caregivers were spouses of the stroke survivor and almost all lived with the survivor. Mean number of years as a caregiver was 4.6 years with a range of 3 months to 22.2 years.

\section{Quantitative Results}

Table 2 presents the mean, standard deviation, minimum and maximum scores for the BCOS and OCBS time and difficulty subscales at T1, T2 and T3. The trends over time using multiple imputation were the same as those seen using the complete cases. The BCOS score increased over time (from T1 to T2 and T2 to T3), indicating consistently positive caregiver life changes (outlook) over time. The OCBS time score consistently decreased over time (from T1 to T2 and T2 to T3), indicating less time spent on caregiving activities. The OCBS difficulty score fluctuated over time, decreasing from $\mathrm{T} 1$ to $\mathrm{T} 2$ and then increasing from T2 to T3, ending with similar scores at T1 and post-intervention (T3).

Table 3 presents the results of the repeated measures ANOVA analysis pooled across the five imputed datasets. Tests showed that all outcomes were normally distributed at all three time points, with the exception of the OCBS difficulty scale at T3. This constituted a minor departure from normality, thus ANOVA was considered appropriate for analyzing outcome differences over time. The BCOS scores increased consistently over time, showing a significant difference at 6 months compared with 2 weeks (mean difference: 5.29, 95\% CI: 0.30-10.28, $p=0.04$ ) and baseline (mean difference: 7.58, 95\% CI: 2.92-12.23, $p=0.001$ ). The OCBS time scores decreased consistently over time, showing significant differences at 6 months compared with baseline (mean difference: $-5.20,95 \% \mathrm{CI}:-0.96$ to $-9.44, p=0.02$ ). The OCBS difficulty scores decreased from $\mathrm{T} 1$ to $\mathrm{T} 2$, but then increased from $\mathrm{T} 2$ to $\mathrm{T} 3$, resulting in no overall difference from baseline to 6 months. The inconsistent trend over time for this score suggests that the initial decrease in score was not sustainable over the 6 months, with a return to the initial level by T3. The results obtained using multiple imputation were similar to those seen in the complete case sensitivity analysis (data not shown).

\section{Qualitative Findings}

Qualitative data analysis revealed five key categories that describe the participants' perceptions of the impact and evaluation of the intervention program. The key categories that emerged include: (a) establishing connections with other caregivers; (b) improved self-care; (c) improved coping skills; (d) improved awareness and use of community supports and (e) improved quality of life. Participants are identified by number and time point of data collection.

\section{Establishing Connections with Other Caregivers}

Many participants felt that the best part of participating in the caregiver group was that it provided an opportunity to interact with other caregivers and to share their personal experiences. As the stroke survivors were at different stages in their recovery, some caregivers had more experience and felt able to provide advice and share their personal experiences and frustrations with those new to the stroke caregiving role. As one participant mentioned, "there is great solace in being with people who are experiencing the same thing, and a great ability to learn from other people and to share experiences" (P2, T3). Participants valued the 


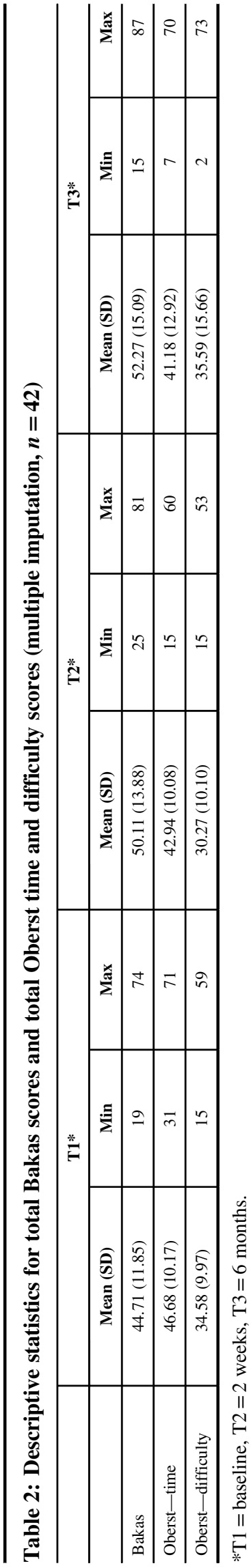

shared understanding they found from the other participants: "Just to have someone, other people in the same room that have gone thorough similar things. We have all gone through it differently but just to have that as a bond that brought us all together" (P9, T2). Establishing connections with other caregivers was important because many participants felt that before attending the group, they did not have any support and were alone in their experiences: "I come here and I see people dealing with it better or dealing with it longer than I am ... it makes me feel better that I am not alone. That's the key word - you are not alone" (P3, T3).

The opportunity to be involved in open and honest communication allowed participants to connect with one another, develop camaraderie and network with other caregivers. One participant explained that as a result of the caregiver support group, they now have friends that they are able to talk to without feeling guilty:

"I have people I can talk to now, just pick up the phone and vent if I need to. And you know they understand that it's just venting, it's nothing other than being able to talk to someone and not feel guilty about it" (P7, T3).

\section{Improved Self-Care}

Participants stated that as caregivers they can get lost in their caregiving duties and forget about their own health and personal needs. They explained that since participating in the group, they now pay more attention to themselves, feel more valuable as an individual and manage their personal health and well-being in a more pro-active manner. They felt that the program emphasized the importance of maintaining personal strength, mental wellness and overall well-being. They realized the impact of how their health and well-being could influence their ability to provide care for the stroke survivor and stated that the "maintenance of the caregiver's health is paramount to the recovery of the stroke survivor" (P27, T3). Through participation in the program, caregivers gave themselves permission to take care of themselves: "A part of that was giving myself permission to have my own life back" (P18, T2). Furthermore, by taking time for themselves, some participants described positive changes in their relationships with the stroke survivor in that they had more energy and patience when providing care.

\section{Improved Coping Skills}

Participants perceived that the program resulted in improved coping skills. They stated that they developed "certain ways of coping with personality changes and that kind of thing in a more light-hearted way" (P16, T3). One participant described how she now copes with her husband's stroke by trying to assess, understand and be more supportive of his triggers and progress in his recovery:

"One thing that came out of it was to try to assess the different things that trigger anger or frustration with my husband, and to try and put it into perspective. One of the people in our group said 'I always look at each thing and say, is this a big deal or a little deal, and if it was a little deal, then let it go but if it was a big deal then address it.'... So I have tried to be more supportive than I was before, and that he is doing well, he is progressing and doing well" (P15, T3). 
Table 3: Repeated measures analysis of variance results for outcome differences over time (pooled results across five imputations, $n=42$ )

\begin{tabular}{|c|c|c|c|c|c|c|}
\hline Time & Time & $\begin{array}{c}\text { Mean difference } \\
\text { (T2-T1, T3-T1, T3-T2) }\end{array}$ & $t$-Statistic & $p$-Value & Lower $95 \%$ CI & Upper $95 \%$ CI \\
\hline \multicolumn{7}{|c|}{ Bakas Caregiving Outcome Scale } \\
\hline 1 & 2 & 5.29 & 2.09 & 0.040 & 0.30 & 10.28 \\
\hline 1 & 3 & 7.58 & 3.19 & 0.001 & 2.92 & 12.23 \\
\hline 2 & 3 & 2.29 & 0.89 & 0.380 & -2.80 & 7.38 \\
\hline \multicolumn{7}{|c|}{ Oberst Caregiving Burden Scale-time subscale } \\
\hline 1 & 2 & -3.22 & -1.45 & 0.15 & 1.15 & -7.59 \\
\hline 1 & 3 & -5.20 & -2.40 & 0.02 & -0.96 & -9.44 \\
\hline 2 & 3 & -1.98 & -0.89 & 0.37 & 2.39 & -6.35 \\
\hline \multicolumn{7}{|c|}{ Oberst Caregiving Burden Scale—difficulty subscale } \\
\hline 1 & 2 & -4.67 & -1.75 & 0.08 & 0.64 & -9.97 \\
\hline 1 & 3 & 1.39 & 0.58 & 0.56 & 6.11 & -3.3 \\
\hline 2 & 3 & 6.05 & 2.32 & 0.02 & 0.88 & 11.23 \\
\hline
\end{tabular}

A caregiver explained that the group sessions taught her "how to better manage the stress and negative emotions that seem to be ever-present" (P27, T3). In some cases, participants improved their coping skills by realizing that it was okay to ask for help. One participant described how seeking help from other people reduced the stress and burden of caregiving:

I think just realizing that I don't have to do everything, but it's also been able to put us in contact with some other cognitive specialists and so that's another burden that has come off me, and now we are getting help and from different venues. And it's working, and it's not just all my burden, that I can sometimes let other people help, and it's okay to do that (P25, T3).

\section{Improved Awareness and Use of Community Supports}

Most participants expressed that participating in the program resulted in improved awareness and use of community supports. Before the program, participants mentioned only having some information about available community support services, often feeling like they were "floundering around in the dark, basically like the blind leading the blind" (P3, T3). The caregiver handbook and session outlined various services available in the community and participants felt that this "really shows you what's out there [and] the help you could get if you know about it" (P2, T3). One participant described how her new knowledge of community supports helped her to better advocate for her mother:

It has had a positive impact on my life as it has given me information to help my mom. As I have found new knowledge about services and stroke, I am better able to advocate for my mom and find other information or resources for her (P18, T3).
Some participants reported actually using the services discussed in the program. One participant stated that his "wife is receiving aphasia services learned about through the program" (P8, T3) and another participant has "used a lot more [home care] services" (P35, T3). For some participants, the knowledge of existing services in itself was seen as valuable: "Even though you might not want to use some of the services we learned about at this point, you know they're out there. It made me more aware of what is available locally" (P7, T3).

\section{Improved Quality of Life}

Finally, most participants felt that their involvement in the program improved their quality of life. They stated that when they started to speak up more, they noticed a change in the level of confidence that the stroke survivor had toward being more independent and feeling more empowered.

[My husband] has become more independent because I am speaking up more, and he is realizing that he can do more than just call on me for help. So it's given him a lot more confidence and opportunities as well. [Also] six months ago I would have generally suggested let's do this or this, now [my husband's] coming up with suggestions. As a communication point, it's more of a partnership again (P4, T3).

As illustrated in the example above, participants also perceived improved communication and collaboration with the stroke survivor, ultimately improving the quality of their relationship. One participant explained that her husband has been more involved in his own care and that he "has become more proactive at planning things to do for himself and planning meals and that sort of thing" (P7, T3). By sharing the responsibility of care and empowering the stroke survivor to be more independent, the participants and their survivors not only felt more comfortable with being away from one another but also the caregiver was able to find more time 
for herself. Participants reported feeling better about themselves and their situations. These positive changes were associated with greater feelings of happiness, strength and understanding of situations:

\begin{abstract}
"Before the program, I felt like ... the light at the end of the tunnel was a locomotive. I don't feel quite like that way now but I understood through this program that I needed outside help and I'm going for it now. I'm not the best person yet but I feel like me is in my grasp now and I am not that horrible person anymore" (P3, T2).
\end{abstract}

\section{Program Recommendations}

Participants were also given the opportunity to provide recommendations for future caregiver group sessions. Their recommendations were related to two categories: (a) program design and group considerations, and (b) timing and transitioning considerations.

The most common recommendations by participants were related to the design of the program. Participants suggested: (a) an increase in the length of each support group session; (b) an increase in the number of sessions and (c) a menu of topics related to stroke caregiving and support that could be selected from by participants. Participants recommended that the size of each support group remain small to facilitate an intimate group where they could openly share their thoughts and concerns. They indicated that peer support might be an appropriate addition to the sessions, as they learned from caregivers who had been there before.

The second category of recommendations was related to appropriate timing of the group to support care transitions. Most participants felt that offering the program earlier on in the stroke trajectory, preferably within the first 3-6 months post stroke, would have had a greater impact on their ability to cope and care for their stroke survivor. There was a recognition that presenting a full program when the stroke occurs may be overwhelming to some caregivers, whereas others may find it very beneficial. Therefore, it was suggested that the content of sessions be tailored to the stage of recovery and needs of caregivers. Some participants recommended offering the program, when the stroke survivor is still in acute care and/or rehabilitation, as this is when they experienced the most confusion, anxiety and uncertainty in regards to the stroke and changes to their daily lives. If information on the impact of stroke and support is not available to caregivers at this point, anxiety and worry can increase and have a detrimental effect on both the caregiver and stroke survivor's ability to cope when they return home. The support group sessions at this point can provide additional support for the cognitive and emotional impact that the stroke may have on the caregiver and the stroke survivor as participants felt that only the physical rehabilitation was addressed in the hospital and outpatient rehabilitation facilities. Participants also recommended that the support group sessions be offered at various times in the day to accommodate the scheduling needs of participants.

\section{DISCUSSION}

Study findings make an important contribution to our understanding of the impact of a new program, FICSS program, on caregiving outcomes for family caregivers of stroke survivors. Study results suggest that the FICSS program may result in reduced caregiver burden and improved life changes resulting from providing care. Qualitative results suggest that the program may have positive impacts on caregiver self-care, coping skills, quality of life, awareness and use of community supports, and social connections with other caregivers.

Caregiver support and education is a necessity to aid in the improvement of the transition of care, ease stress and improve coping strategies for family caregiver of stroke survivors. The evaluation suggests that the FICSS program has positive, shortand long-term outcomes for caregivers of stroke survivors. The study participants also identified that there is a need for an earlier caregiver intervention while the survivor is in hospital during the acute and/or rehabilitation phase of recovery.

The FICSS program was delivered in both rural and urban communities, allowing various caregivers to participate and contribute to the evaluation of the program. Although each group had its unique dynamics, it was very evident that a strong bond or connection had developed among the participants in each of these groups. This finding is consistent with the results of the pilot evaluation of the FICSS program. ${ }^{20}$

Results of this study and the pilot evaluation indicate caregivers' desire for small groups of 6-10 participants to enable sufficient time for all to contribute and actively participate in the program. It was felt that weekly sessions lasting approximately 2 hours provide sufficient time for discussion. Participants recommended that the program be extended to an 8-10 weeks program, thereby allowing time for all of the topics to be presented. This aligns with the findings of a systematic review which suggests "a 3-months psychoeducation with eight sessions might improve the caregivers' family functioning, psychological wellbeing and sense of competence, and also enhance the chance of the stroke survivors remaining at home" 16 (p. 41).

Participants identified that a community setting is preferred over a hospital or rehabilitation facility. Respite care was available upon request during this study and was provided for two individuals. Feedback regarding respite from the participants indicate that for the most part it was not required and if there was to be a respite option it should have specific survivor focused programming to make it worthwhile in terms of the effort of bringing the survivor with them.

There are both similarities and differences in the current findings compared to literature on other stroke caregiver interventions. Consistent with our study findings, Cameron et $\mathrm{al}^{31}$ found improvements in caregiver outcomes (i.e., perceived social support and mastery) in their feasibility and pilot randomized controlled trial of the Timing it Right Stroke Family Support Program. This intervention involved an in-person meeting during acute care followed by six monthly telephone support calls and a guidebook to address caregiver needs. Similarly, a systematic review of psychosocial interventions aimed at improving problem-solving and coping for stroke family caregivers found a positive influence on caregiver psychosocial well-being. ${ }^{16}$ Finally, and inconsistent with our findings, a systematic review of internet-based interventions for caregivers of stroke survivors found no differences in burden, problem-solving, health status and social support after the intervention. $^{32}$ 


\section{Study Limitations}

It is important to acknowledge study limitations that may limit the ability to generalize results. First, participants were generally well educated, and had moderate to high levels of income. Most were born in Canada, were married and a large proportion were receiving community supports. The mean length of time as a caregiver was 4.6 years, well beyond an early point in their stroke caregiving career. Further evaluation of the program is needed with caregivers from lower socio-economic groups, different cultural backgrounds, and in an early point in their caregiving journey. Second, a larger sample would help us to make stronger conclusions about the effects of the intervention over time, and their sustainability over the 6 months period. Finally, it is important to acknowledge the limitations associated with the design itself, as a prospective design with a control group would provide stronger conclusions about the program impact.

\section{Implications for Practice, Education and Research}

The combined impact of the information and the social and emotional support provided through the program will strengthen caregivers' ability, not only to self-manage more effectively but may also facilitate the development of advocacy skills. It is important to explore approaches to engage these caregivers at the "right time," for example, 3-6 months after the stroke, when the information and the contacts yield the greatest opportunity for impact on the caregiver and the stroke survivor. The potential role of a caregiver acting as peer volunteer should be explored further. Meeting with a peer volunteer who has been successful could help ground the new caregiver, providing them with a voice that says, "You will get through this. This can be done." Programs such as this should be introduced as an accepted part of the stroke care pathway such that professionals (neurologists, neuro-care coordinators, family doctors, nurses, therapists and others) recognize the benefits of such a model of caregiver education and support, and recommend it as part of the care plan. In order to expand the reach of this program and to accommodate caregivers who are physically unable to attend the program due to distance, lack of respite care or time constraints, technology for ongoing support such as chat rooms or Skype should be explored.

The program was well supported by the facilitation skills of a social worker paired with an experienced, trained caregiver. To facilitate access to the program, it should be offered at various locations, at various times and throughout the year. The last two sessions should include strategies to assist caregivers to form ongoing support from within the group, or to transition to other sources of ongoing support.

Study findings support the need for interventions such as this to respond to the changing needs of caregivers during the various stages of stroke recovery from acute care to full community re-integration. The FICSS program was designed to respond to the needs of caregivers during the "implementation and adaptation phases" of Cameron's Timing it Right framework. ${ }^{15}$ Programs that address caregiver needs before discharge of the stroke survivor must also be considered and could provide information about or linkages to later interventions such as FICSS. The FICSS program could be incorporated into various clinical practice settings outside of the research study setting. A number of modules of the FICSS program such as Behavior changes: mood, thought and perception; Stress management: managing the rollercoaster; Changing roles in your relationship and Community connections could be provided within the inpatient stroke rehabilitation setting to prepare the caregivers before discharge by interprofessional team members or by stroke peer visitors where those programs exist in organizations. This would support the linkage of caregivers to the full FICSS program after discharge. Within the community, the FICSS program could also be provided within outpatient rehabilitation settings for caregivers to attend while stroke survivors receive their outpatient rehabilitation, to support the development of stroke caregiver peer support programs or as an adjunct to the Living with Stroke Programs to provide support to stroke caregivers.

\section{Conclusions}

Study results suggest that the FICSS program has positive impacts on caregivers including lower burden, improved outlook and improved perceived quality of life, coping skills and connection with other caregivers. Although the participants felt that the program should ideally be offered early in the caregiving journey, all felt it was beneficial for caregivers at any stage in the caregiving experience. Recommendations were made to increase the length of each session and the number of sessions, to offer the program at various times during the day to facilitate participation, and to have an experienced caregiver co-facilitate the session. Further research is required to evaluate the program using a more rigorous design and larger sample, and to explore the impact of different modalities to provide the program.

\section{ACKNOWLEDGMENTS}

The authors would like to thank all the caregiver participants in this study, and the organizations that assisted with recruitment. This study was funded by the Ontario Stroke Network OSN1101000119.

\section{CONFLICT OF INTEREST}

GM and her institution received funding for this project from the Ontario Stroke Network. All other authors declare they have no conflicts of interest.

\section{DisCLOSURES}

GM reports grants from Ontario Stroke Network, during the conduct of the study. RMW, JP, PK, MC, LK, AL and KF have nothing to disclose.

\section{Statement of Authorship}

All authors contributed to the design, conduct, analysis and writing of this project.

\section{REFERENCES}

1. Heart and Stroke Foundation. Mind the connection: preventing stroke and dementia, 2016 Stroke Report; 2016. Available at: http://www.strokebestpractices.ca/wp-content/uploads/2016/06/ HSF_StrokeReport2016_EN-Rev-1.pdf.

2. Mozaffarian D, Benjamin EJ, Go AS, et al. On behalf of the American Heart Association Statistics Committee and Stroke Statistics Committee. Heart disease and stroke statistics - 2016 update: a report from the American Heart Association. Circulation. 2015;133(4):e38-48.

3. O'Connell B, Baker L. Managing as carers of stroke survivors: strategies from the field. Int J Nurs Pract. 2004;10(3):121-6. 
4. Cameron JI, Naglie G, Gignac MA, et al. Randomized clinical trial of the Timing it Right Stroke Family Support Program: research protocol. BMC Health Serv Res. 2014;14(18):1-9.

5. Clark PC, King KB. Comparison of family caregivers: stroke survivors vs. person with Alzheimer's disease. J Gerontol Nurs. 2003;29(2):45-53.

6. White CL, Mayo N, Hanley JA, Wood-Dauphinee S. Evolution of the caregiving experience in the initial 2 years following stroke. Res Nurs Health. 2003;26:177-89.

7. Ogunlana MO, Dada OO, Oyewo OS, Odole AC, Ogunsan MO. Quality of life and burden of informal caregivers of stroke survivors. Hong Kong Physiother J. 2014;32:6-12.

8. Pierce LL, Thompson TL, Govoni AL, Steiner V. Caregivers' incongruence: emotional strain in caring for persons with stroke. Rehabil Nurs. 2012;37(5):258-66.

9. Bakas T, Austin JK, Jessup SL, Williams LS, Oberst MT. Time and difficulties of tasks provided by family caregivers of stroke survivors. J Neurosci Nurs. 2004;36:95-106.

10. Bakas T, Austin JK, Okonkwo KF, Lewis RR, Chadwick L. Needs, concerns, strategies, and advice of stroke caregivers the first 6 months after discharge. J Neurosci Nurs. 2002;34:242-51.

11. Berg A, Palomaki H, Lonnqvist J, Lehtihalmes M, Kaste M. Depression among caregivers of stroke survivors. Stroke. 2005;36:639-43.

12. Han B, Haley WE. Family caregiving for patients with stroke: review and analysis. Stroke. 1999;30:1478-85.

13. Ski C, O'Connell B. Stroke: The increasing complexity of carer needs. J Neurosci Nurs. 2007;39:172-9.

14. Cameron JI, O'Connell C, Foley N, et al. On behalf of the Heart and Stroke Foundation Canadian Stroke Best Practice Committees. Canadian stroke best practice recommendations: managing transitions of care following stroke, Guidelines Update 2016. Int J Stroke. 2016;11(7):807-22.

15. Cameron JI, Gignac MA. "Timing it Right”: a conceptual framework for addressing the support needs of family caregivers to stroke survivors from the hospital to the home. Patient Educ Couns. 2008;70:305-14.

16. Cheng HY, Chair SY, Chau JP. The effectiveness of psychosocial interventions for stroke family caregivers and stroke survivors: a systematic review and meta-analysis. Patient Educ Couns. 2014;95:30-44.

17. Godwin KM, Ostwald SK, Cron SG, Wasserman J. Long-term health-related quality of life of stroke survivors and their spousal caregivers. J Neurosci Nurs. 2013;45(3):147-54.
18. Bakas T, Clark PC, Kelly-Hayes M, et al. Evidence for stroke family caregiver and dyad interventions: a statement for healthcare professionals from the American Heart Association and American Stroke Association. Stroke. 2014;45:2836-52.

19. Heart and Stroke Foundation. Stroke report 2014: Together against a rising tide; 2014. Available at: https://www.heartandstroke.ca/-/ media/pdf-files/canada/stroke-report/hsf-stroke-report-2014.ashx $?$ la=en\&hash $=4$ FD2B 18A0EEDA2A193EFDBBDB983F23B 1 FBD570D.

20. Mores G, Whiteman R, Knobl P, et al. Pilot evaluation of the family informal caregiver stroke self-management program. Can J Neurosci Nurs. 2013;35(2):18-26.

21. Sandelowski M. Whatever happened to qualitative description? Res Nurs Health. 2000;23:334-40.

22. Sandelowski M. What's in a name? Qualitative description revisited. Res Nurs Health. 2010;33:77-84.

23. South-West Local Health Integrated Network (LHIN). Self management toolkit: a resource for health care providers; 2010. Available at: http://www.selfmanagementtoolkit.ca.

24. Tomaszewski G, O'Callaghan C. Self-management in theory and practice: a guide for healthcare providers. Ontario: South-West Local Health Integrated Network (LHIN); 2009, Available at: http://www.thehealthline.ca/displayArticle.aspx?id=1482.

25. Bakas T, Champion V, Perkins SM, Farran CJ, Williams LS. Psychometric testing of the revised 15-item Bakas Caregiving Outcomes Scale. J Nurs Res. 2006;55:346-55.

26. Oberst MT, Thomas SE, Gass KA, Ward SE. Caregiving demands and appraisal of stress among family caregivers. Cancer Nurs. 1989;12:209-15.

27. Bakas T, Burgener SC. Predictors of emotional distress, general health, and caregiving outcomes in family caregivers of stroke survivors. Top Stroke Rehabil. 2002;9:34-45.

28. Yuan Y. Multiple imputation using SAS software. J Stat Softw. 2011;45(6):1-25.

29. Braun V, Clarke V. Using thematic analysis in psychology. Qual Res Psychol. 2006;3(2):77-101.

30. Lincoln YS, Guba EG. Naturalistic inquiry. Thousand Oaks, CA: Sage; 1985.

31. Cameron JI, Naglie G, Green TL, et al. A feasibility and pilot randomized controlled trial of the "Timing it Right Stroke Family Support Program". Clin Rehabil. 2015;29(11):1129-40.

32. Aldehaim AY, Alotaibi FF, Uphold CR, Dang S. The impact of technology-based interventions on informal caregivers of stroke survivors: a systematic review. Telemed E Health. 2015;22 (3):223-31 